\title{
Mediating Test Anxiety through the Testing Effect in Asynchronous, Objective, Online Assessments at the University Level
}

\author{
Daniel Sullivan (Corresponding author) \\ Professor of Global Business Studies, Lerner College of Business and Economics \\ University of Delaware \\ E-mail: dps@udel.edu
}

Received: February 20, 2017

Accepted: February 30, 2017

Published: August 20, 2017

doi:10.5296/jet.v4i2.10777

URL: http://dx.doi.org/10.5296/jet.v4i2.10777

\begin{abstract}
Do asynchronous online evaluations, designed and delivered to engage the testing effect, moderate test anxiety? To answer this question, we surveyed 353 undergraduate and graduate students, drawn from 12 courses, hybrid and online, asking whether the option to take and retake a quiz lessened their text anxiety. Students, no matter the course or level, indicate yes, with more than $90 \%$ of the sample agreeing that the option to retake a quiz reduced test anxiety. We also consider this result with regards to the issues of metacognitive accuracy, student engagement, and learning effectiveness. Nearly $95 \%$ saw the "anytime, anyplace" test-retest option increasing understanding, improving class engagement, and supporting a more effective learning experience. Our findings profile a promising path to reset traditional as well as refine online evaluation pedagogies.
\end{abstract}

Keywords: Test Anxiety, Testing Effect, Online Assessments

\section{Introduction}

In $2010,33 \%$ of US college students enrolled in at least one online class. Presently, more than half of all students in higher education have taken at least one online course. By 2020, forecasts call for roughly 75\% to do so (Allen \& Seaman, 2014; Kena, Aud, Johnson, Wang, Zhang, Rathbun, Kristapovich, 2014). As a rule, an online-only course incorporates some sort of learning management system (LMS) (note 1); increasingly, conventional face-to-face and hybrid formats do the same. The ease, accessibility, and flexibility of progressively sophisticate LMSs to deliver tests encourages migrating assessments online. Wide-ranging, 
long-running studies in conventional classroom settings map effective evaluation pedagogies. Presently, however, significant gaps limit validating, let alone generalizing, reports anchored in bricks and mortar contexts or, for that matter, laboratory settings, to the online domain (Cale, Fowler, \& Rempfer, 2012; Segool, Nathaniel, Mata, \& Gallant 2014).

Consider, for example, the matter of test anxiety. The ever-increasing significance of testing, given the escalating consequences of performance, has made test anxiety an enduring and increasingly worrisome concern (Hembree, 1988; Zeidner, 1998; Sapp, 2013). Currently, anxiety is the most common mental health diagnosis among college students; more than half of students visiting campus clinics cite anxiety as a difficulty and the American College Health Association reports that nearly one in six college students has been diagnosed with or treated for anxiety within the past 12 months (Hoffman, 2015). The unique features of online evaluation, however, complicate interpreting the implications of much of the existing evaluation literature to an online setting. For example, instructors can now easily implement asynchronous testing that is delivered online anytime, anyplace, thereby, authorizing cyber-dispersed students to determine when and where to take a test. Furthermore, administratively flexible LMSs enable efficiently customizing the design and delivery of a test in ways far beyond the reach found in a face-to-face class. Consequently, students increasingly engage online test-taking situations that are utterly unlike that of a completing a one-shot test at a fixed location at a fixed time under the watchful eye of an instructor. Radical change in the context of assessment arguably signals radical change in correlates, such as, test anxiety. Again, however, we struggle to gauge this effect (Stowell and Bennett, 2010; Cassady, 2010; DeBoer, Quellmalz, Davenport, Timms, Herrmann-Abell, Buckley, \& Flanagan, 2014; Kena et al., 2014).

This paper speaks to a facet of this gap. That is, we assess the play of test anxiety, along with that of a potentially powerful moderator, namely the testing effect, within the context of asynchronous, objective, online evaluations. We profile the relationship between test anxiety and the testing effect and, then, within the context of their effect on student engagement and learning effectiveness, document it. Our analytics and explanation, anchored in an evidenced-based mediation in a series of university-level hybrid and online-only classes, profile how the dynamic design and delivery of online, objective evaluations, by engaging the testing effect, diminish text anxiety.

\section{Anchor Concepts and Research Questions}

\subsection{Test Anxiety}

Test anxiety is pervasive, significant, and accelerating (Maloney, Sattizahn, \& Beilock, 2014). It fans a pathology of problems, including fear of negative evaluation, aversion to testing, poor study habits, lower academic achievement, systematic demotivation, and psychological distress (Hembree, 1988; Zeidner, 1998; Cassady, 2010; Segool et al., 2014; Hoffman, 2015). Students experiencing test anxiety tend toward distraction during evaluation, typically struggling to recall relevant information. Poor performance often follows, not because of cognitive limits or under-preparation, but, rather, from the tension of evaluation. Arguably, productive "facilitative anxiety" encourages diligence, promotes creativity, and enhances performance (Munz, Costello, \& Korabik, 1975). However, persistent worry inexorably 
erodes academic achievement (Harpell \& Andrews, 2013; Maloney et al., 2014; Paolini, Harris, \& Griffin, 2016). Worry saps cognitive processing resources, such as attention, awareness, and working memory, which the test-taker would otherwise apply to the quiz. Besides aggravating learning deficits, apprehensive students manifest lower self-esteem, take longer to complete tasks, have higher-state nervousness, expect lower success, and misdirect energy to task-debilitating thoughts. Related problems emerge on several dimensions. Coping with test anxiety, reinforced with memories of earlier consequences, for example, contributes to a propensity to cheat or collude on evaluations (Sapp, 2013). Similarly, ongoing test anxiety fan mental health difficulties, peer detachment, and class disengagement (Hoffman, 2015). The social dynamics of online education-intrinsic impersonality and benign anonymity among cyber-dispersed students often completing work asynchronously - aggravate these circumstances as well as create new contingencies (Stowell \& Bennett, 2010; DeBoer et al., 2014; Kena et al., 2014; Paolini, et al., 2016).

\subsection{The Testing Effect}

The testing effect holds that students acquire and retain knowledge more effectively by being tested on it, rather than through additional drilling, restudying materials, rereading notes, or redoing lessons (Brown, Roediger, \& McDaniel, 2014). The task of taking a test supports test-potentiated learning, thereby reinforcing understanding and improving the productivity of subsequent study and assessment (McDaniel, Anderson, Derbish, \& Morrisette, 2007; Karpicke \& Roediger, 2009). Moving from a single to a series of tests of the same materials engages powerful learning effects, enabling a student to better estimate his level of mastery as well as identify deficiencies. Taking and retaking a test helps students improve metacognitive accuracy by better mapping their mental models to material (Wooldridge, Bugg, McDaniel, and Liu, 2014). Repeated testing relative to additional restudying facilitates knowledge transfer between exams; repeated testing support content mastery that support improving test performance (Dirkx, Kester, \& Kirschner, 2014). Operationally, multiple tests, study opportunities, review of completed quizzes, and item feedback enhance the testing effect (Butler, Karpicke, \& Roediger, 2007). Reports indicate robust test-enhanced learning effects across materials and test formats (Brown et al., 2014).

\subsection{Interaction}

Practitioners and professionals advocate a range of treatments to diminish test anxiety, including biofeedback, combined individual and group counselling, cognitive behavioral therapy, priming competency, hypnotherapy, aromatherapy, and relaxation technique (Hembree; 1988; Ergene, 2003). The scale, scope and logistics of the online education challenge, if not overwhelm, the efficacy of these tools.

Reports on test anxiety and the testing effect literatures indicate that manipulating the design and delivery of a quiz moderate a student's anxiety. The opportunity to take and retake a quiz, by preempting overconfidence, improving calibration, and promoting competence, positively influence a student's self-efficacy and goal orientation while realistically reconciling perfectionism pressures and the fear of failure (Bjork et al., 2013; Carey, 2014). Evidence indicates that reducing a student's worry, via the test-retest instrumentality of the testing effect, eases anxieties (Sitzmann \& Ely, 2014; Cale et. al., 2014). Davidson, House, and Boyd (1984), for instance, reported that $80 \%$ of students in a face-to-face setting reported less test 
anxiety because of the option to retake an exam, even among those who did not use the option. Likewise, Agarwal, Roediger, McDermott, and McDaniel (2014) found that $72 \%$ of their conventional classroom sample reported feeling less anxious about taking unit tests that counted for a grade after practicing with clicker quizzes. Others report that the option to retake exams lowers students' test anxiety and leads to higher student satisfaction with the course and instruction overall (Carey 2014; Brown et al., 2014). Hence, a growing body of evidence suggests the testing effect, enabled via a test-retest pedagogy, improves student's knowledge acquisition, classification, and retention (Butler et al., 2007; Roediger et al., 2011; Dirkx et al., 2014; Abel \& Roediger, 2016, Batsell, Perry, Hanley, \& Hostetter, 2017). Improving familiarity, progressive mastery via improving metacognitive accuracy, as well as processes of "test-potentiated learning," in turn, reportedly diminish a student's test anxiety (Brown et al., 2014).

\subsection{Research Questions}

The ease, accessibility, and flexibility of progressively sophisticated LMSs create potent, scalable, administrative efficient options. Theory suggests that designing and delivering asynchronous, objective evaluations, via an LMS configured to support test-retest procedures, implements a pedagogy that mediates test anxiety by diminishing deficiencies and reducing apprehension, improving metacognitive accuracy, and boosting learning effectiveness. Hence, the purpose of this study is to gauge the influence of the testing effect upon students' self-assessment of test anxiety to asynchronous, objective, online evaluations delivered during online and hybrid courses at the university level. We hypothesize that test-retest opportunities, from the view of the student, diminishes test anxiety. Second, we reason that providing students lower-stress, self-regulated opportunities to demonstrate improving content mastery encourages greater learning engagement. Third, we look at whether the interaction of test-retest opportunities and reduced test anxiety, by enabling students to develop a stronger understanding of class materials, promotes greater student engagement and makes the class a more productive learning experience.

\section{Methodology}

\subsection{Sample}

The study assesses the views of 353 students (167 Undergraduate, 186 Graduate); the gender split was 50.4 male and 49.6 female. Data was collected from 12 sections of a survey course on international business at a public university in the northeast United States. Sections ran between February 2014 and January 2016. This course is a senior-level requirement for all international business majors and an elective for various majors in the University. For MBAs, it is a popular elective. All sections were taught by the same instructor; 6 were graduate, the others undergraduate. 7 courses were delivered online; the others were delivered in a hybrid format. All sections used the Canvas LMS.

\subsection{Data Sources}

At the beginning and the end of a course, each student completed three online surveys. One set of questions used the Westside Test Anxiety Scale (WTAS) to estimate test anxiety (Driscoll, 2007). Students completed the 10-item WTAS before they had attempted an assigned quiz. Survey questions used a 5-point Likert-scale, bounded by 'Always True' and 
'Never True.' At the end of each class, we asked students about their initial expectations of and then experience with online assessments. These questions were derived from the literature and in consultation with the host University's Center for Teaching and Assessment of Learning. These questions also used a 5-point Likert-scale, bounded by 'Strongly Agree' and 'Strongly Disagree.' Completing these surveys, along with one other on aspects of class design and delivery, earned a student credit (a total of $1 \%$ of the final grade). We conducted interviews and discussion with students, both formally and informally, throughout the study.

\subsection{Quiz-Question Design}

Each student completed two types of quizzes. One type, the Core Concepts Check (CCC), tested their mastery of content as reported in the text. The other type, Critical Thinking Scenarios (CTS), tested their ability to apply their understanding of the material to interpret hypothetical scenarios based on relevant themes and principles. In terms of Bloom's Taxonomy, the questions comprising a CCC quiz assessed a student in terms of "remembering, understanding, and analyzing." Questions on a CTS quiz assessed a student in terms of "applying, evaluating, and creating" (Bloom, Engelhart, Furst, \& Krathwohl, 1956).

Laboratory and field studies report weak support of the testing effect when quizzes, based on authentic text materials, emphasize topically related information. These sorts of evaluations devolve into "kill and drill" tasks that produce "inert knowledge" of limited transferability (Roediger et al., 2011). McDaniel et al., 2007; McDaniel, Roediger, and McDermott, (2007) and Wooldridge et al., (2014), however, found evidence of the testing effect for topically related items when questions included explanatory feedback regarding why an answer is correct or incorrect. Therefore, the questions used in this research included feedback.

In many situations, the feedback was directly extracted from the text or from reference materials that has been used in writing the text. For others, particularly those questions geared toward critical thinking, the author developed the explanations. The length of explanations ranged from a sentence to a few paragraphs. Operationally, when a student completed a quiz, Canvas reported the results, indicated if the question had been answered correctly, and presented the corresponding feedback.

\subsection{Question Sources}

Two sources contributed the questions used in the CCC and CTS quizzes. One, the author has steadily generated thousands of questions; this effort continues on an ongoing, albeit far diminished, basis. Two, we tapped the test bank provided by the publisher of the assigned textbook; the author is a coauthor of that text, and it's presently in its ** Edition. The publisher had relied on experienced test question writers to build and refine this resource over the years.

The multiple-choice questions provided by the publisher followed a standard format - that is, a stem, set of alternatives, 3 to 4 distractors, 1 to 2 correct answers, and no explanation. We edited these questions, both in terms of improving the stem's fit with the assigned materials and quiz type as well as developing explanatory feedback. Questions developed by the author applied the same format.

\subsection{Question Banks}

The Canvas LMS supports organizing banks of test questions that are operationally 
independent. For example, one can build any number of different banks organized by chapter, topic, question type, degree of difficulty, etc. These banks, as we explain below, support the Canvas quiz generator algorithm. To date, we have built approximately 140 question banks, organized by chapter (1 through 20) and question type (Core Concept Check or Critical Thinking Scenario). Operationally, for example, we developed 339 questions to test the core concepts linked with Chapter 1 of the assigned text. We distributed those questions across the core concept question banks linked with Chapter 1. We did the same in building the banks of critical thinking scenarios. We repeated this routine for all 20 chapters. Each question bank held 30 to 50 items.

\subsection{Quiz Generator Algorithm}

Options in the Canvas LMS enabled tapping the various question banks linked to a chapter to design a unique quiz for each student for each quiz attempt. That is, Canvas enables selecting "X" questions from the "Y" questions that comprise a particular bank. For example, to design a quiz for Chapter 1, based on the 339 questions filed in the Chapter 1 core concept question banks, we configured Canvas to select, on a student-by-student basis, 1 or 2 question from the Chapter 1 question banks. Canvas then built a quiz by selecting 2 questions from the 47 that comprise bank 1, 1 question from the 45 that comprise bank 2, 2 question from the 41 that comprise bank 3, and so on. Effectively, Canvas generated a relatively unique quiz, for each student, for each attempt, from the 339 hundred questions that comprise the Chapter 1 question banks.

\subsection{Exam Procedures}

Students took two quizzes, a CCC as well as a CTS, per assigned Chapter. In addition, students self-selected any two (UGs) or three (MBAs) unassigned chapters in the text, given their personal interest or professional ambitions. They completed a combined CCC/CTS quiz for each. All quizzes in all classes were delivered online via the Canvas LMS. The LMS delivered the exam questions as a set, allowing students to navigate, as they preferred, among the questions. A student could engage an assigned quiz anytime from the start of the class until its posted deadline. Each quiz accounted for 5\% of the student's total course grade. Quizzes contained 10 to 20 multiple choice questions, were scored upon submission, and the results reported to the student immediately. The LMS shuffled the response set for each question.

We operationalize the testing effect via an expanded test-retake option. Specifically, students had the option to retake a quiz; once was required, but they could choose to retake any quiz, up to five times, to optimize their performance. The choice to retake a quiz, embedded in a context of self-regulated learning, was entirely that of the student. The LMS recorded a student's highest quiz grade, irrespective of its slot in the quiz sequence.

\subsection{Analysis}

The exploratory purpose of this research pushed to develop a general sense of students' interpretation of the research variables. Hence, we assess the frequency distribution of responses to the various survey measures. 


\section{Results}

Response rates for the relevant surveys averaged $98 \%$ across all sections (high of $100 \%$, low of $95 \%$ ). Our initial interest was estimating the scale and scope texts anxiety within the sample. Table 1 reports a WTAS average of 2.84; this suggests that students, on average, indicate moderately high-normal test anxiety. One dimension stands out: "After an exam, I worry about whether I did well enough" with an average rating of 4.22. The WTAS includes two sub-scales: Incapacity and Worry. The former estimates performance ineffectiveness due to memory loss and poor cognitive processing. The latter estimates worrying, which interferes with concentration. Table 1 reports these subscales. The Cronbach's Alphas were acceptable: WTAS, $\alpha=.88$; Incapacity, $\alpha=.78$; and Worry, $\alpha=.73$.

Table 1. Westside Test Anxiety Scale ( $\mathrm{N}=353)$

\begin{tabular}{|l|c|}
\hline Item & $\begin{array}{c}\text { Average, } \\
\text { (Scale } \\
\text { 1-5) }\end{array}$ \\
\hline $\begin{array}{l}\text { 1. The closer I am to a major exam, the harder it is for me to concentrate on the } \\
\text { material. }\end{array}$ & 2.53 \\
\hline $\begin{array}{l}\text { 2. When I study for my exams, I worry that I will not remember the material on the } \\
\text { exam. }\end{array}$ & 3.29 \\
\hline 3. During important exams, I think that I am doing awful or that I may fail. & 2.70 \\
\hline $\begin{array}{l}\text { 4. I lose focus on important exams, and I cannot remember material that I knew } \\
\text { before the exam. }\end{array}$ & 2.60 \\
\hline 5. I finally remember the answer to exam questions after the exam is already over. & 2.91 \\
\hline $\begin{array}{l}\text { 6. I worry so much before a major exam that I am too worn out to do my best on } \\
\text { the exam. }\end{array}$ & 2.65 \\
\hline 7. I feel out of sorts or not really myself when I take important exams. & 2.64 \\
\hline 8. I find that my mind sometimes wanders when I am taking important exams. & 2.70 \\
\hline 9. After an exam, I worry about whether I did well enough. & 3.90 \\
\hline $\begin{array}{l}\text { 10. I struggle with written assignments, or avoid doing them, because I feel that } \\
\text { whatever I do will not be good enough. I want it to be perfect. }\end{array}$ & 2.59 \\
\hline & \\
\hline WTAS Scale Average & 2.84 \\
\hline WTAS Sub-Scale: Incapacity (Items 1, 4, 5, 6, 8 \& 10) & 2.66 \\
\hline WTAS Sub-Scale: Worry (Items 2, 3, 7, \& 9) & 3.12 \\
\hline
\end{tabular}

Table 2 reports the percentage breakdown for test anxiety by degree (Driscoll, 2007). Approximately $35 \%$ of the full sample reported low to normal test anxiety, $48 \%$ reported average high normal to moderately high test anxiety, and $17 \%$ reported high to extremely high test anxiety The American Test Anxieties Association notes that a WTAS score of 3.0 or higher signals students who would likely benefit from intervention (Driscoll, 2007). Some 40\% of the sample reported test anxiety levels exceeding this threshold. 
Table 2. Westside Test Anxiety Scale, Distribution by Range $\quad(\mathrm{N}=353)$

\begin{tabular}{|l|c|c|}
\hline Test Anxiety Level & Range & \% of Sample \\
\hline Comfortably low & $1.0-1.99$ & 9.9 \\
\hline Normal or average & $2.0-2.49$ & 24.8 \\
\hline High normal & $2.5-2.99$ & 25.6 \\
\hline Moderately high & $3.0-3.49$ & 22.5 \\
\hline High test anxiety & $3.5-3.99$ & 13 \\
\hline Extremely high anxiety & $4.0-5.0$ & 4.2 \\
\hline
\end{tabular}

\subsection{Test Anxiety and the Testing Effect}

Table 3 reports that students strongly indicate that taking a quiz online, when and where they wanted, was less stressful than taking a quiz in-class. Likewise, the opportunity to redo a quiz reduced students' apprehension. Again, students had the option to take a quiz multiple times; once was mandatory, but a student could choose to retake any quiz, up to five times. Some $91 \%$ of the sample agreed that the option to retake a quiz reduced test anxiety $(60 \%$ strongly agreed).

Students rated facets of the testing effect strongly, confirming the value of explanatory feedback, the benefit of familiarization, and the chance to gauge their mastery of the material. Essentially, students highlight the play of principles (i.e., calibration, mastery) as well as practical aspects (i.e., practice, familiarization, flexibility) of the test-retest instrumentality. The payoff, in the student's eyes, was quite direct: $60 \%$ strongly agreed, with another $30 \%$ agreeing that the option to redo an assessment helped improve their final grade. Just 1 of the sampled 353 students disagreed.

Table 2, in profiling the WTAS, reports the strong tendency of students to worry, after an exam, about whether one did well enough. The option to retake a quiz, Table 3 shows, diminishes this concern. Fortifying this effect is the choice to set the LMS to record the highest quiz score, irrespective of its place in the sequence of attempts. Some $70 \%$ of students saw the alternative-namely, average all scores on all attempts - as a deterrent to retaking a quiz.

\subsection{Learning Experience and Engagement}

Table 4 profiles students' view of aspects of the testing effect within the context of the class as an effective learning experience. Student across all courses and levels consistently saw the test-retest option supporting the usefulness of the class, improving their understanding of the materials, and identifying gaps in their knowledge. More than $95 \%$ of the sample endorsed these outcomes; in no case did anyone disagree. Relatedly, students saw the item feedback included in the quiz questions supporting these outcomes. Many indicated that their improved understanding of the material, by virtue of their understanding as to why an answer was correct or incorrect, helped them to earn a higher score on subsequent attempts.

The results indicate that the test-retest option, by providing low-stress opportunities to develop and demonstrate content mastery, motivated student engagement. Table 4 shows that 
across the full sample, nearly all students linked the option to redo a quiz with improving their final grade. Data, both survey as well as interview, found students linked higher performance to their investment of additional study time. Essentially, the data suggest that the option to boost their grade, via the retest option, motivated student to engage, with the likely payoff of doing so, a higher quiz score. Relatedly, we had asked, "Between quiz attempts, I spent time restudying class materials in the effort to improve my performance." The timeline was set in 15 minute increments, up to one hour, at which point, it turned to "an hour or more." On average, UGs and MBA reported investing approximately 18 and 21 minutes, respectively, in mastering the assigned material between quizzes.

Table 3. Measures of Test Anxiety and Testing Effect $(\mathrm{N}=353)$

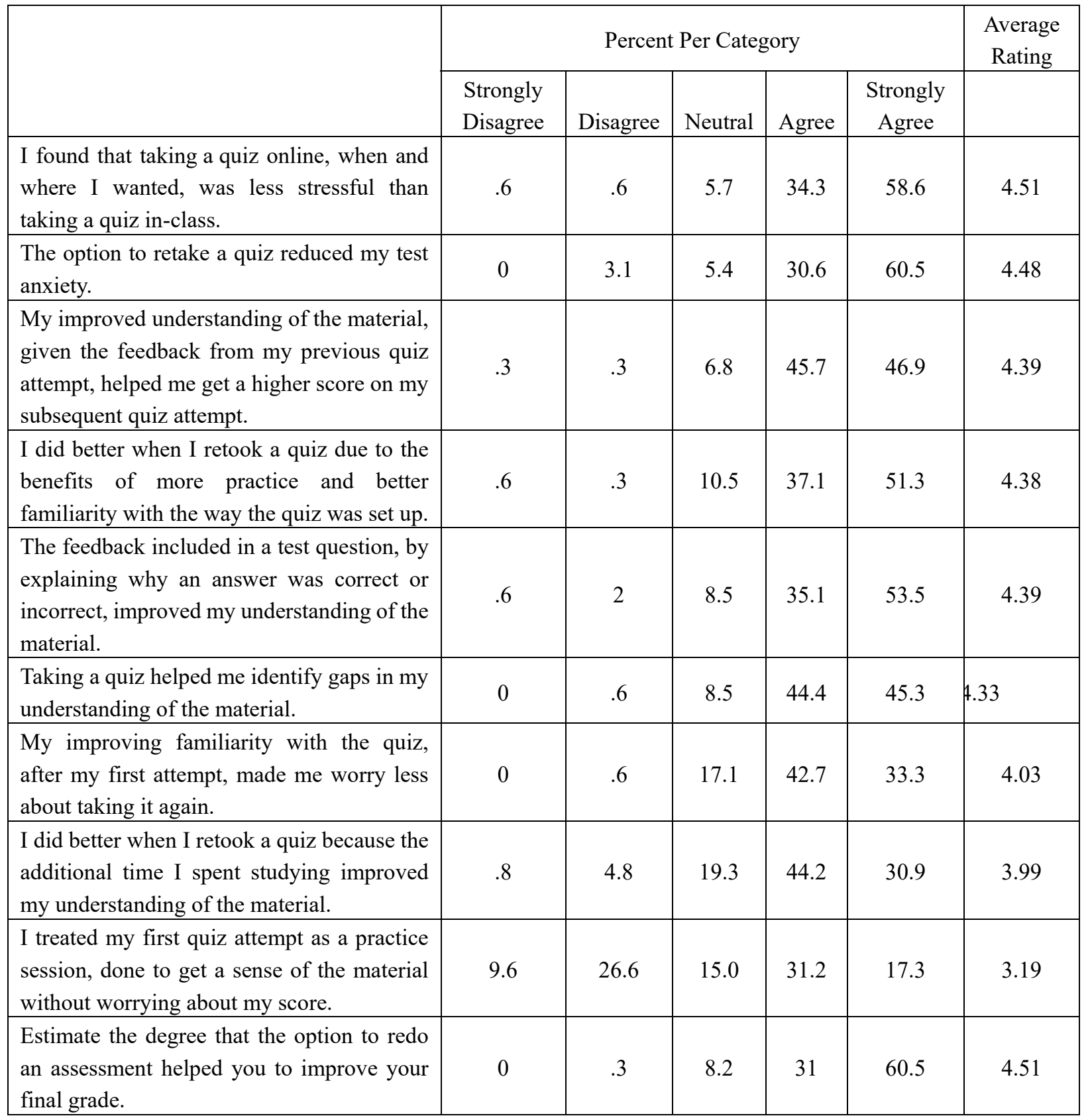


Table 4. Measures of Learning Engagement $\quad(\mathrm{N}=353)$

\begin{tabular}{|l|c|c|c|c|c|c|}
\hline & \multicolumn{3}{|c|}{ Percent Per Category } & $\begin{array}{c}\text { Average } \\
\text { Rating }\end{array}$ \\
\cline { 2 - 7 } & $\begin{array}{l}\text { Strongly } \\
\text { Disagree }\end{array}$ & Disagree & Neutral & Agree & $\begin{array}{c}\text { Strongly } \\
\text { Agree }\end{array}$ & \\
\hline $\begin{array}{l}\text { The option to retake quizzes } \\
\text { made this class a more effective } \\
\text { learning experience for me. }\end{array}$ & 0 & .6 & 4.8 & 36.8 & 57.8 & 4.51 \\
\hline $\begin{array}{l}\text { Retaking quizzes led me to } \\
\text { develop a stronger understanding } \\
\text { of class materials. }\end{array}$ & .3 & 0 & 5.9 & 38.6 & 55.1 & 4.48 \\
\hline $\begin{array}{l}\text { Counting the time before and } \\
\text { between quiz attempts, the } \\
\text { option to retake a quiz to earn a } \\
\text { higher score led me to spend } \\
\text { more time studying. }\end{array}$ & .3 & 3.7 & 14.2 & 43.5 & 38.4 & 4.15 \\
\hline $\begin{array}{l}\text { The option to retake quizzes } \\
\text { motivated me to work harder } \\
\text { than I would otherwise have } \\
\text { done if I had been allowed to } \\
\text { take a quiz only once. }\end{array}$ & .3 & 10.5 & 15.9 & 33.8 & 39.5 & 4.01 \\
\hline $\begin{array}{l}\text { Between quiz attempts, I spent } \\
\text { time restudying class materials in } \\
\text { the effort to improve my } \\
\text { performance. }\end{array}$ & 1.4 & 11.1 & 20.2 & 40.9 & 26.4 & 3.80 \\
\hline $\begin{array}{l}\text { I prefer taking a quiz one time, } \\
\text { get my grade, and be done with it } \\
\text { rather than having to retake it. }\end{array}$ & 33.2 & 44.4 & 12.8 & 7.7 & 1.7 & 2.01 \\
\hline
\end{tabular}

\section{Discussion}

The accelerating migration of evaluations from the classroom to online platforms creates opportunities to rethink and reset assessment and evaluation. Concurrently, migrating evaluation models raises questions about a range of design and delivery contingencies (Stowell \& Bennett, 2010; Bjork, Dunlosky, \& Kornell, 2013; Brown et al., 2014). Improving our discussion of both led to assessing, in terms of online evaluations delivered asynchronously during online-only and hybrid courses at the university level. Key questions centered on students' view of the test-retest option to mediate test anxiety and the resulting implications to metacognitive accuracy, engagement, and effectiveness of the learning experience.

Students strongly support the proposition that the test-retest option, as designed and delivered in this study, diminished test anxiety- $97 \%$ of the sample agreed, $3 \%$ were neutral, and none 
disagreed. In absolute terms, this finding builds on earlier studies. Davidson et al., (1984) reported $80 \%$, whereas Agarwal et al., (2014) report that $72 \%$, of the respective samples reported feeling less test anxiety when given the option to retake an exam. In relative terms, our finding signals that the instrumentality of online evaluation, within a test-retest context, provides a promising path to boost these levels significantly. Our findings, both survey and interview, highlights the capacity of the testing effect to mediate the causes and correlates of test anxiety in online evaluations by providing "anytime, anyplace" low-stress opportunities to fail without fatal consequences. Similarly, the option to take and retake a test in an ethos of "practice makes perfect" helped transforms evaluation from one-shot competency to progressive mastery. More precisely, the data indicate that the test-retest option, as implemented in this research, enabled a student to (1) diminish deficiencies and reduce anxiety, (2) improve metacognitive accuracy, and (3) optimize the learning experience. In turn, we address each.

\subsection{Diminishing Deficiencies and Reducing Anxiety}

The deficit hypothesis holds that test anxiety moderates test performance because less competent test-takers experience higher levels of test anxiety during an assessment (Sommer $\&$ Arendasy, 2014). In general, repeated testing benefits the test-taker by improving knowledge acquisition, classification, and retention (Butler et al., 2007; Karpicke, 2009; Dirkx et al., 2014; Agarwal et al., 2014; Abel \& Roediger, 2016, Batsell, et al., 2017). The instrumentality of the testing effect, by offering a student a series of low-stress assessments, enables him or her to translate growing competency-based experience into the self-confidence that reduces, if not neutralizes, performance anxiety (Hembree, 1988; Ergene, 2003; Carey, 2014; Brown et al., 2014).

This literature suggests that some sorts of tests, particularly multiple-choice formats, help students who, by answering incorrectly, then prime their brain for what's coming later, both on that quiz, as well as subsequent assessments. Again, the online evaluations used multiple choice questions. Each quiz attempt, particularly following the review of a completed quiz and its explanation of the correct response, modifies how one interprets, classifies, and stores the information contained in the questions - indeed, 94\% of the students agreed that retaking quizzes developed a stronger understanding of class materials and some $90 \%$ endorsed the usefulness of the feedback included in a test question. Effectively, online test-retest opportunities support a robust pedagogy to help less competent test-takers progressively develop expertise, thereby reducing a cause of test anxiety (Sapp, 2013; Sommer \& Arendasy, 2014).

Furthermore, taking a test informs students as to what they know and what they do not know (Brown et al., 2014; Carey, 2014). Poor performance on a test, rather than signifying yet another failure, transforms in the context of the test-retest option. Instead, failure becomes a challenge to overcome by translating additional preparation and improving mastery of the material into a higher score on the next attempt. Aware they have the option, as they see fit, to retake a test provides a stress-free method to help students calibrate what they know as well as what they did not - to that effect, some $90 \%$ of the sample agreed that taking a quiz helped them to identify gaps in their understanding of the material. Progressively improving mastery, besides boosting the productivity of subsequent study, lowers the dread about the extreme 
stakes of success or failure on a single attempt (Sapp, 2013; Cale et al., 2013). More eloquently, Carey (2014:1) notes that "each attempt drives home the information in a way that studying as usual does not. We fail, but we fail forward." As the student "fails forward," given the opportunity to retake a quiz, he or she actively takes responsibility for her own learning and succeeding. Taking responsibility for aspects of the evaluation process - that is, in our design, a student had a big say in when, where, and how often to attempt a quiz-supports goal-oriented behavior and promotes self-regulated learning that bolster personal esteem, academic performance, and career potential (Bjork et al., 2013; Sitzmann \& Ely, 2014; Cale et. al., 2014).

Our results suggest that students saw the choice to determine the place and time of succeeding, or, as the case may be, the chance to "fail forward," as a key moderator of test anxiety. Follow-up interviews found the "anytime, anyplace" instrumentality supported adaptive coping strategies that helped students mediate test stress. For instance, students explained the benefit of interleaving breaks, both study and recreation, between quiz attempts, reviewing material to clarify confusing or frustrating questions, taking a "breather" to regain their "karma" after a poor performance, and avoiding the insidious undercurrent of stress during a class-based exam (Sapp, 2013). As such, 93\% of the sample agreed that taking a quiz online, when and where I wanted, was less stressful than taking a quiz in-class. This relationship between an "anytime, anyplace" quiz and test anxiety suggest that online options provide robust opportunities, relative to traditional classroom environments, for a student to diffuse his or her anxieties via direct, preferred methods.

\subsection{Improving Metacognitive Accuracy}

The relationship between what students initially learn, their metacognitive judgments of what they think they know, and how they choose to study has a complex relationship with test performance, and by extension, implications to test anxiety. The discrepancy reduction framework suggests that students target a goal state of knowledge and then allocate their study to reduce the gap between their current knowledge state and their ideal. Many students struggle to set realistic goals, with debilitating implications to choosing what, when, and how to study (Karpicke, 2009). The challenge of calibrating knowledge means students often decide to stop studying before they have mastered the material. Moreover, some over-concentrate their study immediately, rather than leveraging evenly-spaced segments, before taking the test (Bjork, et al., 2007).

Test enhanced-learning processes, operationalized via the test-retest option, encourage deliberate engagement by objectively and realistically informing students as to what they know and what they do not know (Brown et al., 2014). Our data indicate that students commonly invested additional time, between quiz attempts, mastering the assigned material. Furthermore, the completed quiz attempts, by enabling students to better calibrate their mastery of materials, improved their metacognitive accuracy, as indicated by earning a higher score on subsequent attempts (Karpicke, 2009). Collectively, our results indicate that low-stress test-retest opportunities helped students differentiate what they do know and what they do not know well; improving understanding coupled with improving task familiarization, in turn, boosted their performance (Bjork et al., 2013; Brown et al., 2014). 


\subsection{Optimizing the Learning Experience}

Students agreed that the option to retake a quiz made their course a more effective learning experience. Given the opportunity to invest effort to earn the highest possible grade, students consistently exploited the opportunity. Their views, quiz behavior, and explanations consistently speak to the potential of self-regulated learning and goal-oriented behavior to support positive performance (Bjork et al., 2013; Eum \& Rice, 2014; Sitzmann \& Ely, 2014). For example, related workflow surveys determined that between quiz attempts, students spent additional time restudying class materials; on average, students reported investing an additional 20 minutes in mastering the assigned material between quiz attempts. The Canvas LMS, among other measures, reports the test sequence for each student, profiling the score, timing, and duration of each attempt. Assessing this data shows that the typical student completed approximately 40 quizzes to generate the scores for the assigned 10-chapter quiz slots over the course; these 10 scores determined $50 \%$ of their final grade. Canvas reports that, on average, a student spent 14 minutes completing a quiz. Effectively, the typical student spent an additional 420 minutes (30 quiz retakes @ 14 minutes) working on self-motivated and self-regulated quiz retakes. Factoring in the reported average of 20 minutes of additional study time means that the typical student who completed 30 "extra" quizzes voluntarily invested an "additional" 940 minutes into mastering the material, improving their understanding, and optimizing their performance.

Ultimately, as seen in Table 4, students saw the option to retake quizzes helping them to develop a stronger understanding of class materials--some $95 \%$ of the respondents indicate the test-retest option made the class a more effective learning experience that motivated them to work harder, study more, and do better. Authorizing students the choice to work as hard as they see fit to optimize their performance, after satisfying a minimum expectation, resulted in many exemplifying self-regulated learning to reach a desired level of achievement (Bjork et al., 2013; Sitzmann \& Ely, 2014). As such, the test-retest option provided a path for students to reduce test anxiety by playing to processes of self-efficacy. That is, a student's independent choice to master material supported her belief in her capacity to execute behaviors necessary to produce specific performance outcomes as well as then bolstering her confidence in self-regulating motivation, behavior, and social environment (Bandura, 1993). As an aside, a common request from both outstanding and struggling students were additional quiz attempts; in the case of the former, retakes supported perfectionism, in the latter, improving mastery, and in both cases, additional effort and learning. In all cases, accomplishing one's goal, in turn, resulted in improved understanding of the class material as well as, in line with goal-oriented behavior and self-regulated learning, higher satisfaction with the course experience.

\section{Conclusion}

In absolute terms, the proliferation of high-stakes tests, both in measuring achievement as well as allocating options, intensifies test anxiety. In relative terms, the expanding scale and scope of online education signals a likely inflection point in assessing learning and administering evaluations, an enduring cause of test anxiety. The results of this study identify a promising path to reduce text anxiety, via asynchronous, objective online evaluations, while 
also bolstering their performance and improving the learning experience, through less stress, improved mastery, and greater self-efficacy. The views of students across multiple courses and over multiple time frames saw this evaluation pedagogy reducing test anxiety, promoting engagement, encouraging learning, and, ultimately creating opportunities to succeed. As such, our results, besides highlighting the interplay between the testing effect and test anxiety in online evaluations, help shape emergent discussions about evaluation models.

In theory, the ease, accessibility, and flexibility of online learning systems through progressively robust LMSs calls for rethinking, if not resetting, conventional, class-based evaluation models. We submit our results strongly support doing so, documenting a robust pedagogy to reduce test anxiety. In principle, our findings suggest that leveraging the testing effect via an administratively efficient, scale-insensitive, relatively inexpensive LMS-anchored pedagogy's reduced text anxiety, as well as improved student engagement and learning effectiveness. In practice, the capacity of an LMS to organize multiple question banks and coordinate multiple quiz attempts supports administratively-efficient, effectively-delivered, student-centric evaluation models. Our experience suggests that upon building the course scaffolding, it is straightforward to configure an LMS to design and deliver an astonishing variety of quizzes. Looking forward, the Canvas LMS, like other platforms, will grow increasingly robust, streamlining existing procedures as well as expanding features, notably item analysis, quiz delivery, and student tracking.

\section{References}

Abel, M., \& Roediger, H. L. (2016). Comparing the testing effect under blocked and mixed practice: The mnemonic benefits of retrieval practice are not affected by practice format. Memory \& Cognition, 1-12.

Agarwal, P. K., D'Antonio, L., Roediger, H. L., McDermott, K. B., \& McDaniel, M. A. (2014). Classroom-based programs of retrieval practice reduce middle school and high school students' test anxiety. Journal of Applied Research in Memory and Cognition, 3(3), 131-139. http://dx.doi.org/10.1016/j.jarmac.2014.07.002

Allen, I. E., \& Seaman, J. (2014). Grade change: Tracking online education in the United States, 2013. Babson Survey Research Group and Quahog Research Group, LLC. 3(5), 2014.

Bandura, A. (1993). Perceived self-efficacy in cognitive development and functioning. Educational Psychologist, 28(2), 117-148. http://dx.doi.org/10.1207/s15326985ep2802_3

Batsell, W. R., Perry, J. L., Hanley, E., \& Hostetter, A. B. (2017). Ecological Validity of the Testing Effect the Use of Daily Quizzes in Introductory Psychology. Teaching of Psychology, 44(1), 18-23. https://doi.org/10.1177/0098628316677492

Bjork, R. A., Dunlosky, J., \& Kornell, N. (2013). Self-regulated learning: Beliefs, techniques, and illusions. Annual Review of Psychology, 64, 417-444. http://dx.doi.org/10.1146/annurev -psych-113011-143823

Bloom, B. S., Engelhart, M., Furst, E. J., Hill, W. H., \& Krathwohl, D. R. (1956). Taxonomy of educational objectives: the classification of educational goals. Handbook I: Cognitive 
domain. New York: David McKay Co.

Brown, P. C., Roediger III, H. L., \& McDaniel, M. A. (2014). Make it stick: The science of successful learning. Boston: Harvard University Press. https://doi.org/10.4159/9780674419 377

Butler, A. C., Karpicke, J. D., \& Roediger III, H. L. (2007). The effect of type and timing of feedback on learning from multiple-choice tests. Journal of Experimental Psychology: Applied, 13(4), 273. http://dx.doi.org/10.1037/1076-898x.13.4.273

Cale, N., Fowler, C., \& Rempfer, M. (2012). Test anxiety and learning potential in college students. Undergraduate Research Journal for the Human Sciences, 11(1).

Carey, B. (2014). How we learn: The surprising truth about when, where, and why it happens. Random House LLC.

Cassady, J. C. (2010). Test anxiety: Contemporary theories and implications for learning. In J.C. Cassady., ed. Anxiety in schools: The causes, consequences, and solutions for academic anxieties. Vol. 2. Peter Lang, 2010.

Davidson, W. B., House, W. J., \& Boyd, T. L. (1984). A test-retest policy for introductory psychology courses. Teaching of Psychology, 11(3), 182-184. https://doi.org/10.1177/009862 838401100320

DeBoer, G. E., Quellmalz, E. S., Davenport, J. L., Timms, M. J., Herrmann-Abell, C. F., Buckley, B. C., \& Flanagan, J. C. (2014). Comparing three online testing modalities. Journal of Research in Science Teaching, 51(4), 523-554. http://dx.doi.org/10.1002/tea.21145

Dirkx, K. J., Kester, L., \& Kirschner, P. A. (2014). The testing effect for learning principles and procedures from texts. The Journal of Educational Research. http://dx.doi.org/10.1080/ 00220671.2013 .823370

Driscoll, R. (2007). Westside test anxiety scale validation. Online Submission. Retrieved from http://files.eric.ed.gov/fulltext/ED495968.pdf.

Ergene, T. (2003). Effective interventions on test anxiety reduction a meta-analysis. School Psychology International, 24(3), 313-328. http://dx.doi.org/10.1177/01430343030243004

Eum, K., \& Rice, K. G. (2011). Test anxiety, perfectionism, goal orientation, and academic performance. Anxiety, Stress, \& Coping, 24(2), 167-178. http://dx.doi.org/10.1080/10615806. 2010.488723

Hembree, R. (1988). Correlates, causes, effects, and treatment of test anxiety. Review of Educational Research, 58(1), 47-77. http://dx.doi.org/10.3102/00346543058001047

Hoffman, J. (2015). Anxious students strain college mental health centers. The New York Times, May 27.

Karpicke, J. D. (2009). Metacognitive control and strategy selection: Deciding to practice retrieval during learning. Journal of Experimental Psychology: General, 138, 469-486. 
http://dx.doi.org/10.1037/a0017341

Karpicke, J. D., \& Roediger, H. L. (2008). The critical importance of retrieval for learning. Science, 319, 966-968. http://dx.doi.org/10.1126/science.1152408

Maloney, E. A., Sattizahn, J. R., \& Beilock, S. L. (2014). Anxiety and cognition. Wiley Interdisciplinary Reviews: Cognitive Science, 5(4), 403-411. http://dx.doi.org/10.1002/wcs. 1299

McDaniel, M. A., Anderson, J. L., Derbish, M. H., \& Morrisette, N. (2007). Testing the testing effect in the classroom. European Journal of Cognitive Psychology, 19(4-5), 494-513. http://dx.doi.org/10.1080/09541440701326154

McDaniel, M. A., Roediger, H. L., \& McDermott, K. B. (2007). Generalizing test-enhanced learning from the laboratory to the classroom. Psychonomic Bulletin \& Review, 14(2), 200-206. http://dx.doi.org/10.3758/BF03194052

Munz, D. C., Costello, C. T., \& Korabik, K. (1975). A further test of the Inverted-U hypothesis relating achievement anxiety and academic test performance. The Journal of Psychology, 89(1), 39-47. http://dx.doi.org/10.1080/00223980.1975.9923904

Paolini, S., Harris, N. C., \& Griffin, A. S. (2016). Learning anxiety in interactions with the outgroup: Towards a learning model of anxiety and stress in intergroup contact. Group Processes \& Intergroup Relations, 19(3), 275-313. https://doi.org/10.1177/1368430 215572265

Sapp, M. (2013). Test anxiety: Applied research, assessment, and treatment interventions. University Press of America.

Sarason, S. B. (1959). What research says about test anxiety in elementary school children. NEA Journal, 48, 26-27.

Segool, N. K., Nathaniel, P., Mata, A. D., \& Gallant, J. (2014). Cognitive behavioral model of test anxiety in a high-stakes context: an exploratory study. School Mental Health, 6(1), 50-61. http://dx.doi.org/10.1007/s12310-013-9111-7

Sitzmann, T., \& Ely, K. (2011). A meta-analysis of self-regulated learning in work-related training and educational attainment: what we know and where we need to go. Psychological Bulletin, 137(3), 421. http://dx.doi.org/10.1037/a0022777

Sommer, M., \& Arendasy, M. E. (2014). Comparing different explanations of the effect of test anxiety on respondents' test scores. Intelligence, 42, 115-127. http://dx.doi.org/10.1016/j. intell.2013.11.003

Stowell, J. R., \& Bennett, D. (2010). Effects of online testing on student exam performance and test anxiety. Journal of Educational Computing Research, 42(2), 161-171. http://dx.doi.org/ 10.2190/EC.42.2.b

Wooldridge, C. L., Bugg, J. M., McDaniel, M. A., \& Liu, Y. (2014). The testing effect with authentic educational materials: A cautionary note. Journal of Applied Research in Memory 
and Cognition, 3(3), 214-221. http://dx.doi.org/10.1016/j.jarmac.2014.07.001

Zeidner, M. (1998). Test anxiety: The state of the art. Springer.

Note

Note 1. An LMS, such as Canvas, Moodle, Edmodo, Schoology, Docebo, SkillSoft, or Blackboard, is a software application that helps an instructor design and deliver a face-to-face, hybrid, or online course.

\section{Copyright Disclaimer}

Copyright reserved by the author(s).

This article is an open-access article distributed under the terms and conditions of the Creative Commons Attribution license (http://creativecommons.org/licenses/by/3.0/). 